\title{
Development and validation of an individualized survivorship care plan (ISCP) for women with endometrial cancer during the transition of the end of active treatment to the cancer survivorship
}

by Johanne Hébert and Lise Fillion

\begin{abstract}
Many cancer survivors finish their treatment without knowing the associated health risks and few are prepared to handle their health needs in the survivorship phase. Moreover, practical guides for follow-up care are not available and survivors' psychological and social needs often go unassessed. In this article, we propose the development and implementation of an individualized follow-up care plan (IFCP) after active treatment for women with endometrial cancers (WEC) to meet their needs for information and to facilitate the transition to the survivorship phase.
\end{abstract}

Background: The after-treatment phase is a distinct phase that is still neglected in the oncological continuum of care. It is the transition between two phases in the care trajectory-treatment and survivorship - that gives rise to many challenges for survivors, care providers and the healthcare system alike.

Research goal: Aiming to facilitate the transition between the end of active treatment and the cancer survivorship phases, we pursued two objectives: 1) Develop an individualized follow-up care plan (IFCP) based on both the literature and the perspective of WEC, healthcare professionals involved with the target clientele and oncology outreach managers, and 2) Have this IFCP validated by an interdisciplinary team.

Methodology: For the first objective, WEC-related needs at the end of active treatment (immediate end, three months and six months), as well as the perceptions of health professionals and oncology outreach managers were gathered by interview and group discussion on the benefit of an IFCP, its content and desired format. A content analysis of the interview data was performed using the Miles

\section{ABOUT THE AUTHORS}

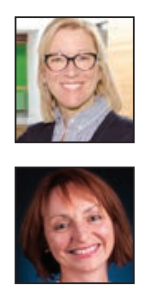

Johanne Hébert, LPN, M.Sc., Ph.D(c), Professor, Department of Nursing, Université du Québec à Rimouski (UQAR)

Lise Fillion, LPN., Ph.D, Full professor, Faculty of Nursing, Université Laval

\begin{abstract}
Address for correspondance: Johanne Hébert, LPN, M.Sc., Ph.D(c), Professor, Department of Nursing, Université du Québec à Rimouski, Lévis Campus, 1595 Alphonse-Desjardins Blvd., Lévis QC G6V OA6

Phone: 418-833-8800, ext. 3243; Email: johanne_hebert@uqar.ca
\end{abstract} DOI: $10.5737 / 236880762713342$ and Huberman approach (2003). For the second objective, an iterative consultation process with health professionals allowed for validation by consensus. These two objectives are the first qualitative phase of a mixed-methods sequential exploratory design that will make the development of an IFCP possible. In the second phase, we conducted a feasibility study of the implementation of the IFCP during the end of active treatment transition to cancer survivorship transition. This will be the subject of a second article.

Results: The interviews ( $n=47$ ) revealed WECs' lack of preparation for the transition from the end of active treatment to the cancer survivorship. The following needs were specified: information (80\%), emotional support, particularly to overcome their fear of recurrence (75\%), the management of physical symptoms (45\%), and support for adapting to change (45\%). The data gathered from healthcare professionals and outreach managers support the utility of an IFCP in meeting these needs. The iterative validation process by the interdisciplinary team made consensus on the format and content possible. The final version of the IFCP is seen as a tool for information and communication in the survivorship phase. Some obstacles to its transfer to clinical practice are reported.

Conclusion: This study presents the entire process that led to the development of an IFCP that integrates both the needs of endometrial cancer survivors and the opinions of healthcare professionals and the oncology outreach managers organizing this care. Indications on how the IFCP could be implemented within this organization are also formulated.

Key words: transition, end of active treatment, needs, cancer survivorship, individualized follow-up care plan

Tn Canada, gynecological cancers account for $12 \%$ of new 1 cancers in women and, among them, endometrial cancer is the most common-indeed, it is the fourth most frequent cancer in women (Canadian Cancer Society, [CCS] 2015). Although the incidence has increased by $2.6 \%$ since 2004 , improvement in prevention, screening and treatment favour the relative survivorship of more than $80 \%$ of endometrial cancer patients (CCS, 2015).

The end of active cancer treatment and the start of survivorship is a distinct, but neglected phase in the continuum of care. This phase is a period of transition (between treatment and survivorship) that poses many challenges to survivors, care providers and the healthcare system (Hewitt, Greenfield, \& Stovall, 2006; Jones \& Grunfeld, 2011). For survivors, the end of active treatment is often a complex time for their continuum of care and on a personal level. As such, it can be a major 
life event. Although the end of treatment is generally experienced as positive, a growing number of studies document the challenges of this phase in the continuum of care (Beesley et al., 2008; Jones et al., 2012). The consequences of cancer and its treatment bring physical, informational, emotional, psychological, social, practical and spiritual challenges that can compromise quality of life (Fitch, Porter, \& Page, 2008; Hewitt et al., 2006; Steele \& Fitch, 2008). For care providers and the healthcare system, the diversity of the patients, diagnoses, treatments and potential side effects increase the complexity of care in the survivorship phase (Dahl, Wittrup, Vaeggemose, Petersen \& Blaakaer, 2013). This complexity is further heightened by the lack of guidelines on how to orient care in the survivorship phase (Landier, 2009).

Studies suggest that WEC do not feel prepared for the post-treatment and cancer survivorship phase (Jones et al., 2012; Nicolaije et al., 2012). Many of these survivors' needs (physical, informational, psychological and social) go unmet (Beesley et al., 2008; Nicolaije et al., 2012; Steele \& Fitch, 2008). Physical needs and long-lasting and late side effects are reported (Abbott-Anderson \& Kwekkeboom, 2012; Jones et al., 2012; Vaz et al., 2011; Vollrath, Zenger, Singer, Einenkel \& Hinz, 2013). Wu and Harden (2015) describe the difficulty of managing physical symptoms, like fatigue, pain, sleep troubles and cognitive problems.

Several studies documented the need at the end of active treatment for information on prevention and risks of recurrence, the possibility of secondary cancers and other health problems associated with the treatments and the illness, long-lasting and late side effects, physical and psychological treatment, and psychological and social resources (Brennan, Butow, Spillane, \& Boyle, 2010; Greimel, Lahousen, Dorfer, Lambauer, \& Lang, 2011; Nicolaije et al., 2012; Papadakos et al., 2012). Moreover, gynecological cancer survivors describe the difficulty of accessing information and resources, as well as the difficulty of communicating with their healthcare professionals (Jones et al., 2012; Nicolaije et al., 2012).

Gynecological cancers and their treatments also have repercussions on patients' psychological and social needs all along the continuum of care. Psychological concerns about recurrence of the illness, long-lasting and late side effects, and the possibility of limited survival are all common (Dahl et al., 2013; Simard et al., 2013). Fear of cancer recurrence (FCR) is among the most frequently reported problem in all cancer survivors (Armes et al., 2009; Jefford et al., 2011; Simard et al., 2013) and in most women with gynecological cancers (Beesley et al., 2008; Dahl et al., 2013; Fitch \& Steele, 2010; Steele \& Fitch, 2008). Studies support the association between FCR, distress, depression, anxiety and avoidance/intrusion in cancer survivors (Simard et al., 2013). FCR is also associated with a greater occurrence or a greater number of physical symptoms such as side effects, fatigue, pain, body image/appearance in survivors (Simard et al., 2013).

To meet patient needs in the transition between end of active treatment and cancer survivorship, a key report by the Institute of Medicine (IOM) titled "From cancer patient to cancer survivor: lost in transition" lays out recommendations for follow-up survivorship care. The authors highlight that the survivorship phase is a distinct yet neglected phase in the continuum of care. This phase is poorly coordinated and many survivors and care providers do not receive adequate information on follow-up care, the late and long-term effects of cancer and its treatments for long-term health (Hewitt et al., 2006). In fact, studies show that the management of symptoms and survivor support in this phase are fragmented and poorly coordinated (Jefford et al., 2011; Sprague et al., 2013). Access to information on the post-treatment period (Jones et al., 2012; Beckjord et al., 2008) and maintaining support services through this phase of the care trajectory (Jones et al., 2012; Marbach \& Griffie, 2011) are recommended. Information and support that help meet these specific needs could prevent distress (Steele \& Fitch, 2008), contribute to the empowerment of WEC and, thus, facilitate the transition process (Meleis et al., 2000). Relevant information, support for the development of competencies and trust favour survivors' commitment in self-managing their care (McCorkle et al., 2011).

To help meet needs for information and support, patient-focused care models recognize the importance of clarifying the roles and responsibilities of each player in follow-up care in the survivorship phase (Epstein \& Street, 2007). However necessary to coordinating care, this clarification is opaque and remains undefined in this phase of the continuum of care (Aubin et al., 2011; Bober et al., 2009).

Since it informs, communicates, clarifies, and coordinates the care (Curcio, Lambe, Schneider, \& Khan, 2012; Faul et al., 2012; Forsythe et al., 2013; McCorkle et al., 2011), the clinical tool of submitting an individualized follow-up care plan (IFCP) to patients finishing their active cancer treatment is suggested. This is, in fact, one of the IOM's recommendations (Hewitt et al., 2006). The IFCP is an element of continuity of quality care (Howell et al., 2011). It is a partnership between the survivor and the caregiving team (McCorkle et al., 2011). Few gynecological cancer survivors currently have an IFCP (Brothers, Easley, Salani, \& Andersen, 2013; Grover et al., 2012; Sabatino et al., 2013; Salani, 2013).

It is recommended, when developing IFCPs, to consider the perspectives of the people diagnosed with the targeted cancers and the opinions of the interdisciplinary team members involved in their cases (Baravelli et al., 2009; Burg, Lopez, Dailey, Keller, \& Prendergast, 2009; McCorkle et al., 2011; Smith, Singh-Carlson, Downie, Payeur, \& Wai, 2011). However, few studies have documented the IFCP development process in a way that includes these stakeholders' perceptions. To our knowledge, no such study has been conducted in Quebec.

This article presents the first phase of the primary author's doctoral study. The objectives are the development and validation of an IFCP for women with endometrial cancers following adjuvant treatments.

\section{METHODOLOGY}

\section{Study design and participants}

This doctoral study is based on a sequential exploratory design (Creswell \& Plano Clark, 2011). This design is made up of a development phase followed by an exploration of the implementation (feasibility study) phase. The first qualitative sequence presented in this article has two objectives: the development and the validation of the IFCP. 
Table 1: Key concepts and indicators selected for the development of content for the IFCP

\begin{tabular}{|l|l|l|l|}
\hline Actor groups & Concepts & Indicators /Questionnaires & Theories/Models \\
\hline WEC & $\begin{array}{l}\text { Transition / Needs } \\
\text { Fear of recurrence } \\
\text { Empowerment }\end{array}$ & $\begin{array}{l}\text { Needs (SUNS) } \\
\text { Distress (FCRI) } \\
\text { Empowerment (HeiQ) }\end{array}$ & $\begin{array}{l}\text { Meleis et al. (2000) and } \\
\text { Fitch (1994) }\end{array}$ \\
\hline $\begin{array}{l}\text { Professionals/ } \\
\text { Outreach }\end{array}$ & $\begin{array}{l}\text { Resources } \\
\text { Effects of IFCP } \\
\text { Impact of IFCP }\end{array}$ & $\begin{array}{l}\text { Goal, objective and resources to implement for the IFCP } \\
\text { Effect of IFCP on WEC and other professionals } \\
\text { Overall impact of implementation }\end{array}$ & $\begin{array}{l}\text { Patton (1997) adapted by } \\
\text { Fillion et al. (2011) }\end{array}$ \\
\hline
\end{tabular}

N.B.: SUNS = Survivor Unmet Needs Survey (Campbell et al., 2011); FCRI = Fear of Cancer Recurrence Inventory (Simard

\& Savard, 2015); HeiQ = Health Education Impact Questionnaire (Osborne et al., 2007).

To meet the first objective, that is developing an IFCP for WEC, an intentional sample was formed of two groups of stakeholders: (1) women with endometrial cancers with adjuvant treatments; and, (2) healthcare professionals (i.e., gynecooncologists, radio-oncologists, hemato-oncologists, general practitioners within and from outside the medical institution, nurses from the specialized team and radio-oncology nurses, psycho-oncologists, nutritionists, social workers, kinesiologists) working with this target population and oncology outreach managers (clinicians and decision makers involved in oncological care). The inclusion criteria for the WEC were the following: (a) have an endometrial cancer and have received adjuvant treatments (chemotherapy/radiotherapy/brachytherapy) alone or in combination; (b) have finished active cancer treatment; and, (c) be 18 years or older. The selection criteria allowed for a diversity of experiences and took three precise moments of the transition period into account (end of treatments, three-month follow-up and six-month follow-up). For the two other groups, the inclusion criteria were to be involved in providing or organizing care for the target clientele.

To meet the second objective (validating the IFCP), we used the Delphi method (Brown, 1968), which is intended to obtain the most consensual response possible from a group of experts. Two focus groups were created with participants from the health professionals group (nurses and specialists) in order to validate the content of the IFCP tool and the proposed format.

\section{Procedure for WEC}

The nurse navigator of the oncology team specialized in gynecological cancers selected eligible patients and informed them of the study. Those interested in receiving more information about the study were invited to meet the student researcher or a research assistant (RA) who told them of the protocol and invited them to join. Patients who accepted to participate in the study filled out a consent form and took part in a semi-structured interview lasting 30-45 minutes. The study received the ethical approval of the university hospital centre in which it was conducted.

\section{Collection of Qualitative Data}

Qualitative data were collected from all study participants by individual interview or focus groups. Interview guides and discussions were developed from the central topics of the theoretical models selected for the doctoral study: the mid-range transition theory of Meleis, Sawyer, Im, Hilfinger Messias, and Schumacher (2000), the oncology supportive care framework (Fitch, 1994) and the Patton model (1997) often used in the implementation of an innovative practice in the health field. The collection of these data sought to describe overall needs of WEC and the perceptions of health professionals and outreach managers in the utility, content and format of an IFCP to meet these needs. The key concepts and indicators, their link with the theory, and their selection according to the group of stakeholders being targeted is summarized in Table 1. Simultaneously, the PubMed, CINAHL, EMBASE and Cochrane Library databases were searched using the following key words: "survivorship care plans, follow-up care, cancer care plan, cancer survivorship care, survivorship care planning, cancer treatment summary, post-treatment cancer care, cancer transitions, cancer survivors, gynecologic cancer survivors." Moreover, many websites for cancer organizations, such as the Princess Margaret Cancer Centre, the National Cancer Institute (NCI), the Canadian and American Cancer Societies, the American Society of Clinical Oncology (ASCO), the LIVESTRONG Foundation, the Society of Gynecologic Oncology (SGO), Journey Forward, the Australian Cancer Survivorship Centre, Macmillan Cancer Support, Cancer Council Victoria, were consulted for their relevancy on the study subject.

\section{Data Analyses}

The descriptive data describe the sample (sociodemographic and clinical variables). The qualitative data analysis was conducted in three steps according to the Miles and Huberman approach (2003): (1) data reduction (organizing the data); (2) data display (organized assembly of the information drawn from the data); and (3) conclusion drawing/verification (final conclusions on the body of data). The individual and group interviews were digitally recorded and transcribed in full. Several categories emerged from a thorough reading of the verbatim transcription and were grouped in topics according to a first list of codes from the study's conceptual framework and the key variables displayed in Table 2. The data were organized and codified using the NVivo10 software. An operational definition for each code was coined. The interpretation of these themes intended, first, to describe and specify the needs of the target population and, second, to describe the 
Table 2: Methodological framework for qualitative data

\begin{tabular}{|c|c|}
\hline $\begin{array}{l}\text { Meleis et al. (2000); Fitch (1994) } \\
\text { WEC }\end{array}$ & $\begin{array}{l}\text { Patton (1997), adapted by Fillion et al. (2011) } \\
\text { Health professionals and outreach managers }\end{array}$ \\
\hline $\begin{array}{l}\text { Nature of the transition } \\
\text { Awareness, level of involvement, change and difference, space in } \\
\text { time, critical points and events } \\
\text { Needs in survivorship period } \\
\text { Physical, informational, emotional, psychological, social, spiritual, } \\
\text { practical } \\
\text { Facilitating and hindering transition conditions } \\
\text { Meaning given to the event, beliefs and attitudes, socioeconomic } \\
\text { status, community resources, preparation and knowledge } \\
\text { Adaptation to change } \\
\text { Active-passive adaptation strategies, preparedness for post-treatment } \\
\text { phase } \\
\text { Process indicators } \\
\text { Feeling connected, interaction with others and the } \\
\text { environment, situation in time and space, building of confidence and } \\
\text { coping skills }\end{array}$ & $\begin{array}{l}\text { Initial situation and resources needed for introduction of IFCP } \\
\text { Goal, needs, objectives of the IFCP, justification and relevance of } \\
\text { the IFCP, credibility of the approach } \\
\text { Activities done with available resources } \\
\text { Roles, resources needed for introducing the IFCP at the end of } \\
\text { treatment, available clinical and organizational tools } \\
\text { Participants' reaction to introducing the IFCP } \\
\text { Hope, advantages, difficulties and drawbacks in introducing the } \\
\text { IFCP } \\
\text { Participants get involved in introducing the IFCP and in the } \\
\text { activities } \\
\text { Implementation of the IFCP, involvement of nurses and members } \\
\text { of the interdisciplinary team } \\
\text { Effects of the IFCP on the person in transition / empowerment for } \\
\text { survivorship } \\
\text { Evaluating and responding to needs; facilitating person-centred } \\
\text { care } \\
\text { Improving knowledge of resources, perceived support, satisfaction } \\
\text { Increasing care quality; services or resources provided over time } \\
\text { Effects on continuity of care, practices and behavioural changes } \\
\text { Impact of IFCP on nursing role, new practices, interactions } \\
\text { between team members and first line } \\
\text { Overall intentional and non-intentional impact } \\
\text { Significance and consequences of implementation, nursing } \\
\text { role, satisfaction and quality of life in a long-term perspective }\end{array}$ \\
\hline
\end{tabular}

perceptions and expectations about content, benefits and the desired format of an IFCP at the end of active cancer treatment for all participants.

To ensure the study's credibility and reliability, the data collection methods were triangulated. In addition to the qualitative data gathered in individual interviews, the data from selected studies were added for a better understanding of the development process (for the content and format) of existing IFCPs. Moreover, a validation of the codification process was conducted between the main researcher and an independent team of researchers until a consensus on the operational definition of each code was reached (Miles \& Huberman, 2003).

\section{Development of an IFCP}

Following the analysis of the data set (both interviews and literature), a first draft of an IFCP was written by the student researcher. Drawing on the Delphi method (Brown, 1968), the content was validated with the members of the interdisciplinary team working with the clientele under study. A process for reiterative consultation of the members of this team was implemented. The consultation process continued until consensus was reached on the content and format of the IFCP to be implemented in this organization and with this clientele.

\section{RESULTS}

The sample characteristics are presented first. Then, the results are presented around the themes that arose for each group of stakeholders. The description of the consultation process for the content validation and the development of the IFCP close this process.

The sample was made up of 19 WEC (nine in their last treatment [T0]; four at the 3-month follow-up point [T1]; and, six at the 6-month follow-up point [T2]), 24 health professionals (five nurses; nine medical specialists; five general practitioners; two psycho-oncologists; one nutritionist; one social worker; and one kinesiologist) and four oncology outreach managers. The sociodemographic and medical characteristics of the WEC are shown in Table 3.

\section{Needs Expressed by the Target Clientele}

At the three measurement points, the WEC expressed several needs. These were grouped under five themes and illustrated by a representative quote. They are presented in Table 4. The majority of participants acknowledge that several of their needs have gone unmet. The first theme is the need for information. More than $80 \%$ expressed needs for information and 


\begin{tabular}{|l|c|c|}
\hline \multicolumn{3}{|l|}{ Table 3: WEC sociodemographic and medical characteristics } \\
\hline Characteristics & Participants & $\%$ \\
\hline Age $(n=19)$ & & \\
\hline 44-60 yrs. & 9 & 47.4 \\
\hline 61 yrs. + & 10 & 52.6 \\
\hline Marital status ( $n=18)$ & & \\
\hline Single & 3 & 16.7 \\
\hline Married & 8 & 44.4 \\
\hline Common-law & 4 & 22.2 \\
\hline Widowed & 3 & 16.7 \\
\hline Level of education ( $n=18)$ & & \\
\hline Elementary & 2 & 11.1 \\
\hline Secondary & 4 & 22.2 \\
\hline Trade diploma & 3 & 16.7 \\
\hline College & 1 & 5.6 \\
\hline University & 8 & 44.4 \\
\hline Employment status ( $n=18)$ & & \\
\hline Full-time & 3 & 16.7 \\
\hline Part-time & 1 & 5.6 \\
\hline Unemployed & 1 & 5.6 \\
\hline Disability & 3 & 16.7 \\
\hline Retired & 10 & 55.6 \\
\hline Family phys. ( $n=19$ ) & 18 & 94.7 \\
\hline Treatments received ( $n=20)$ & 3 & 10.0 \\
\hline Chemotherapy only & 5 & 25.0 \\
\hline Chemotherapy \& brachytherapy & 2 & 10.0 \\
\hline Radiotherapy \& brachytherapy & & 40.0 \\
\hline Brachytherapy only & & \\
\hline $\begin{array}{l}\text { Chemotherapy \& radiotherapy } \\
\text { \& brachytherapy }\end{array}$ & & \\
\hline & & \\
\hline
\end{tabular}

Table 4: Five themes grouping together the needs expressed by WEC

\begin{tabular}{|c|c|}
\hline Themes & Verbatim accounts \\
\hline 1. Information & $\begin{array}{l}\text { "I left and I didn't know anything... I knew I } \\
\text { had an appointment in three months with } \\
\text { the oncologist, and in six months with the } \\
\text { radiologist." (WEC 19) } \\
\text { "I would have liked to know that there are } \\
\text { support groups for the fear of recurrence and to } \\
\text { prepare us for what happens next... You are told } \\
\text { this, but you have so many feelings and so many } \\
\text { things to manage." (WEC 12) } \\
\text { "I have a bit of anger because I found out my } \\
\text { cancer grade and stage three weeks ago, which } \\
\text { I'd never been told, and which I didn't even know } \\
\text { existed." (WEC 12). }\end{array}$ \\
\hline $\begin{array}{l}\text { 2. Emotional } \\
\text { support for fear } \\
\text { of recurrence }\end{array}$ & $\begin{array}{l}\text { "Sometimes I feel so unwell... then you ask } \\
\text { yourself if it hasn't made its way in somewhere } \\
\text { else." (WEC 8) } \\
\text { "My black cloud, I think is my head, which won't } \\
\text { stop thinking about that." (WEC 12) } \\
\text { "The hamster keeps turning on its wheel... } \\
\text { As much as you'd like to stop it, it can't be } \\
\text { controlled like that." (WEC 9) } \\
\text { "Will it come back.... how will I know?" (WEC 2) }\end{array}$ \\
\hline $\begin{array}{l}\text { 3. Relational } \\
\text { support }\end{array}$ & $\begin{array}{l}\text { "After the treatments, people are under the } \\
\text { impression that we're cured. Then it becomes } \\
\text { more difficult to talk about it. We get the feeling } \\
\text { that people need us to move on." (WEC 6) } \\
\text { "I had two ladies I would call, who'd had } \\
\text { cancer, and they would tell me: 'Oh yes, that's } \\
\text { very normal." (WEC 7) } \\
\text { "It's so important to talk to someone who isn't } \\
\text { afraid of what I'm going to say." (WEC 2) }\end{array}$ \\
\hline $\begin{array}{l}\text { 4. Management } \\
\text { of long-lasting } \\
\text { physical } \\
\text { symptoms }\end{array}$ & $\begin{array}{l}\text { "It's as if, instead of having } 24 \text { hours in my day, I } \\
\text { had half... my energy was so reduced." (WEC 6) } \\
\text { "The fatigue: when will it go away? Will things go } \\
\text { back to the way they were? Stools: will they go } \\
\text { back to the way they were? It's ridiculous; my } \\
\text { stomach is swelling like crazy." (WEC19) }\end{array}$ \\
\hline $\begin{array}{l}\text { 5. Adaptation } \\
\text { to change }\end{array}$ & $\begin{array}{l}\text { "It's like I had to realign my life so that this new } \\
\text { life would be the one I really live now." (WEC 6) } \\
\text { "I'm under reconstruction... I took a year } \\
\text { to rebuild myself, but now, it's my social } \\
\text { reconstruction that needs to be redone, fine- } \\
\text { tuned." (WEC 12) }\end{array}$ \\
\hline
\end{tabular}

The fourth theme was physical needs. WEC (45\%) reported the need for support in managing various symptoms, such as fatigue, gastro-intestinal problems, pain, neuropathy, sleep trouble, and sexual problems that last and affect their quality of life.

The fifth theme is in regards to the adaptation process. Participants (45\%) reported a need for psychological support (e.g., from health professionals or other cancer survivors) to help them adapt to the psychological changes brought by the illness, the treatments, and the FCR. 
Among the other themes WEC reported, let us mention that $40 \%$ discussed the importance of keeping contact with the family physician during and after their illness, and 30\% talked about the difficulty of going back to work because of lasting physical symptoms.

\section{Perceptions from Health Professionals and Outreach Managers}

Table 5 presents the perceptions that health professionals and outreach managers have of the IFCP, by theme and by component.

The first theme looks at the use of the IFCP and includes three components, namely, information, information continuity, and support for WEC. It was first acknowledged that information given after treatment is rudimentary and irregular, and dependent on the members of the team and on the patient finishing her treatment. Many participants (79\%) maintained that the IFCP could be an information tool for WEC: a summary of the long-lasting side effects and symptoms to watch for (what), the people to contact in case of need (who), and the upcoming follow-ups (when). Others (54\%) mentioned that the information contained in the IFCP would be a useful written reference for professionals outside the specialized environment (in particular, the family physician), for example to know the history of the treatment period and the side effects to watch for. This would allow for information continuity and, thereby, improve the continuity of care, and it could also promote communication among professionals. As a written reference, the IFCP would provide support to WEC and could facilitate the transition from the end of active treatment to survivorship. The meeting at which the IFCP would be delivered to the patient who has reached the end of treatment would be reassuring and provide an opportunity to take stock at that point on the continuum of care, while making the patient aware of what to watch for during the post-treatment phase.

The second theme deals with aspects of the IFCP's content. It includes all the components proposed by the IOM (Hewitt et al., 2006) that were brought out by most participants. We note however that only $14 \%$ mentioned the inclusion of information on healthy behaviours to be adopted by cancer survivors. The validation of content step clarified the amount of information to include (characteristics of the disease and treatments, and a list of symptoms). Participants also emphasized that the information should be easy to locate and that too much information could increase anxiety. Health professionals also mentioned that information should be simple (use of simple terms) to facilitate comprehension.

Finally, five components emerge in the last theme, which looks at the ideal format. The described IFCP is short, with checkboxes to make it quick to fill out, and should be easy to use (several participants specified a computerized document). Some recommended that the IFCP be customized, that is, that it be adapted according to each person's needs. Others preferred that the IFCP have a general section and a customized section. Most recommended a basic standardized model whose content is adapted to the person and cancer site with blank spaces to complete the information.

When asked about the best person and the best time to deliver the IFCP to a patient, 50\% designated the oncology nurse navigator, 21\% the medical specialist, and 11\% other care professionals who are meaningful for the person. The most desirable times mentioned for giving the IFCP to the person were the last treatment $(21 \%)$ or near the end of treatment (18\%). Questions were also raised about the IFCP's added value for health professionals and the organization. Barriers in terms of time, resources (staff and financial) and care trajectory (logistics) and, more specifically, the feasibility of meeting with each patient finishing active treatment were mentioned. Many questioned the extra work (time) involved in filling out the IFCP (on paper or computer) and delivering it to the patient. With regard to resources, the notions of responsibility (who will do what) and interdisciplinarity (how to share the responsibility) were raised.

\section{Validation and presentation of the final IFCP}

A first draft of the IFCP was created that included all the recommendations made by both groups of actors interviewed and from the literature. The draft was submitted for a validation process. A participatory and iterative approach was carried out in two steps: 1) presentation of the IFCP for validation by two groups of actors (medical specialists and nurses), using a consensus approach for each of the items proposed in the IFCP; and 2) meetings with the oncology nurse navigators for the fine-tuning and controls of the IFCP's digital version. This validation process required three group meetings and six individual meetings, for a total of 20 hours in the development of a final version of the IFCP. First, three one-hour focus group discussions were held with participants from the health professionals group, namely, oncology nurse navigators $(n=2)$ and medical specialists $(n=8)$. Each item of the IFCP was presented using PowerPoint, to validate the content and proposed format of the tool (IFCP). Then, six 90-minute meetings were held with the oncology nurse navigators involved in the implementation, to integrate recommendations into the IFCP and to fine-tune the tool.

The final IFCP (version 4) contains the following: (1) personal information; (2) treatment summary: cancer type, phase, and grade; surgery (date type, particulars, surgeon); types of treatment received: chemotherapy (drugs, cycles, particulars, start and end dates, treatment location), radiotherapy (region, total dose, number of fractions, particulars, radiation oncologist, start and end dates, treatment location), brachytherapy (method, total dose, particulars, radiation oncologist, start and end dates, treatment location), hormonal therapy (drugs, dose, particulars, start and end dates), end of treatment (adjuvant treatment end date and treatment-related toxicities); (3) potential long-term side effects; (4) monitoring of symptoms to report to the physician; (5) specialist-recommended examinations and follow-ups; (6) overall health follow-up; (7) contacts; (8) resources; (9) personal health objectives; and, (10) recommended healthy behaviours (exercise, nutrition, smoking, alcohol, UV exposure). Several sections include scroll-down menus and standardized information for endometrial cancers to make the IFCP easier to fill out.

\section{DISCUSSION}

Phase I of the doctoral study included two objectives. The first was to develop an IFCP that would take into account the needs of WEC at the end of active treatment, as well as the perceptions that health professionals and outreach managers have on the 


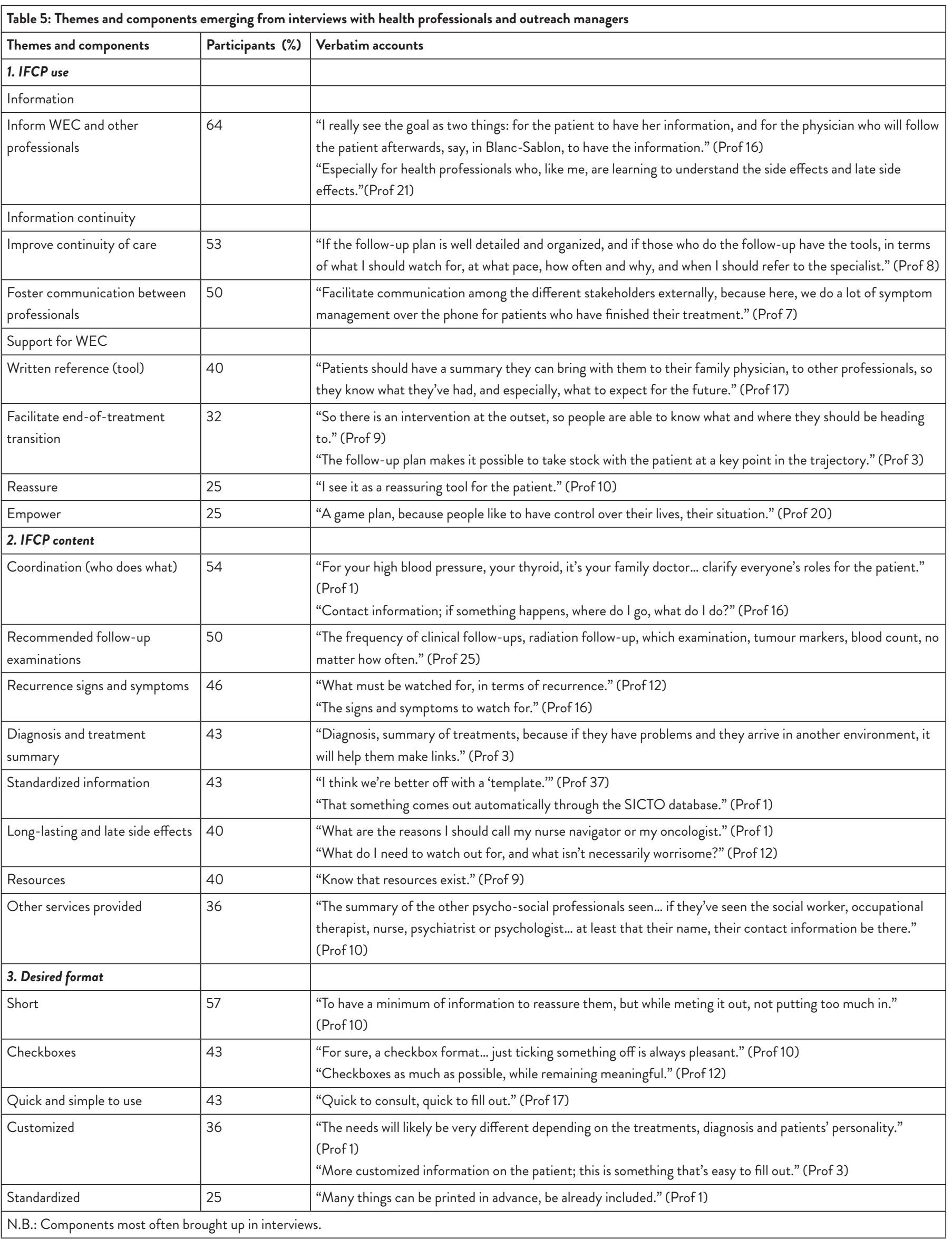


IFCP: it is perceived as an information and communication tool whose implementation is needed to facilitate the transition to survivorship at the end of active treatment. The second objective was to validate the content. The iterative approach made it possible to reach a consensus in the interdisciplinary team.

\section{Taking into Account the Needs of WEC}

What makes this IFCP unique is that it takes into account the needs expressed by WEC. The clarification of these needs reinforces the results of other studies deploring the fact that cancer patients are not sufficiently prepared for survivorship (Burg et al., 2009; Jones et al., 2012). Our results suggest that WEC have a number of needs not being met, affecting their quality of life. Many express their difficulty in returning to a "normal" life when they have persistent physical symptoms and lack information about the symptoms they should be watching for (what is normal and what is not) and about what post-treatment follow-up is recommended. The results of our study add to other findings of a persistent and deplorable lack of information (Jones et al., 2012; Nicolaije et al., 2012). That women with gynecologic cancers need to receive information at the end of active treatment, however, has been well documented (Brennan et al., 2010; Burg et al., 2009; Marbach \& Griffie, 2011; Nicolaije et al., 2012; Papadakos et al., 2012). The WEC in our study expressed a need for information on the risk of recurrence, on the long-lasting and late side physical and psychosocial effects of the treatments, on the psychosocial support available, and on other health problems related to treatment and the disease.

Most study participants expressed fear that the disease would return and a feeling that a sword of Damocles hangs over their heads. Emotional and psychological needs are common during this phase, more specifically, concerns about recurrence, about long-lasting and late side effects, and about the possibility of a reduced life expectancy (Dahl et al., 2013; Simard et al., 2013). Some studies suggest that survivors with high levels of fear of recurrence are more likely to develop anxiety problems (Simard \& Savard, 2015). There is a correspondence between the expression of FCR by WEC and the feeling of anxiety frequently observed in the year following the end of the initial treatment and often associated with a fear of the disease recurring (Harrington et al., 2010; Salani, 2013). Finally, WEC report problems adapting to the changes triggered by the disease and the treatments, and to a new post-treatment reality. The study by Thorne and Stajduhar (2012) highlights the adaptation problems and confused emotions (insecurity, vulnerability, and feelings of loss and abandonment) that are experienced at the end of treatment, a time that also triggers new worries about physical health, emotional well-being, social relations, work, and financial resources.

\section{The contribution of health professionals}

Our study also brings out how health professionals view the IFCP as an information tool for the cancer survivor and for health professionals and, particularly, for the family physician. The IFCP is perceived as an information continuity tool that could improve continuity of care and interprofessional communication. It is specified that the IFCP would be a tool used to direct supportive care, thereby strengthening the capacity of WEC to better meet their own needs. Developed in collaboration with WEC in order to inform them and involve them in self-managing their health, the IFCP would contribute to greater care coordination (McCorkle et al., 2011). The impact on WEC empowerment could facilitate the end-of-treatment transition to survivorship and have an indirect "reassuring" effect.

The literature has also highlighted the contribution an IFCP can make to improving care coordination and communication between caregivers during this phase of the care trajectory (Curcio et al., 2012; Hewitt et al., 2006; Jefford et al., 2011). The IFCP is said to make up an element in the continuity and quality of care (Howell et al., 2011), and to improve the standard of care (Haq et al., 2013). The selected process provides an example of an interdisciplinary approach for developing and implementing an IFCP, as recommended in the literature (Howell et al., 2011; Jefford et al., 2011).

\section{Specifying the Content and Format of the IFCP and the Time of Delivery to the Patient}

Our results support the IOM's recommendations, since they contain all the content elements it suggests. According to Stricker et al. (2011), only 59\% of existing IFCPs contain the IOM-proposed content (Hewitt et al., 2006). In addition to these recommendations, participants also suggest that simple, easy-to-understand (non-medical) language be used and that the information contained in the IFCP be relevant to the survivor (Burg et al., 2009). In this sense, too much general information (possible symptoms of recurrence or potential side effects) can trigger anxiety and dissuade people from using the IFCP (Haq et al., 2013). Some studies suggest including a section on psychological, legal, and financial problems (Baravelli et al., 2009). Our results also clarify the importance of including some form of action plan, by including a section on the resource persons to contact in order to meet specific needs. In particular, a person in charge of the follow-up should be listed in the IFCP (Baravelli et al., 2009; Howell et al., 2011) to facilitate coordination of the post-treatment phase. In this sense, the IFCP developed meets the recommendation that the instrument be customized and not be "one size fits all" (Brennan, Gormally, Butow, Boyle, \& Spillane, 2014). What's more, giving the patient the IFCP at the end of treatment ensures that the right information is provided at the right time (Haq et al., 2013).

With regard to format, the IFCP should be short, and quick and easy to use. Our study suggests the use of some customized sections and some that are standardized to the type of cancer. The use of an electronic format is recommended, as is giving a paper copy to the survivor at the last treatment. As discussed in other studies (Baravelli et al., 2009; Dulko et al., 2013), the nurse would be the professional appointed to complete and deliver the IFCP near the end of treatment or shortly thereafter (Mayer, Gerstel, Leak, \& Smith, 2012). An end-oftreatment meeting would normalize the transition to survivorship at the end of active treatment, introduce the IFCP as an information and coordination tool, respond to questions raised, direct to resources where necessary, and encourage the transition to the family physician (Jefford et al., 2011). WEC maintain that the family physician should be involved throughout the care trajectory, particularly during survivorship care. 
Along those lines, the study by Smith et al. (2011) suggests that the transition be planned between the specialists and the family physician to encourage continuity of care during the transition to the end of treatment and survivorship.

\section{Anticipated Barriers to Implementation}

The study results do however note some barriers to the development and implementation of an IFCP, which have already been reported in other studies. In fact, the difficulty of clarifying the roles and responsibilities of each team member in terms of filling out and delivering the IFCP has been raised, as have the lack of time for customized development and implementation, and the lack of resources (staff and financial) (Brennan et al., 2014; Dulko et al., 2013).

\section{CONCLUSION}

The process makes it possible to describe the development of an IFCP that incorporates the needs of survivors, as well as of health professionals and outreach managers. Furthermore,

\section{REFERENCES}

Abbott-Anderson, K., \& Kwekkeboom, K.L. (2012). A systematic review of sexual concerns reported by gynecological cancer survivors. Gynecologic Oncology, 124(3), 477-489.

Armes, J., Crowe, M., Colbourne, L., Morgan, H., Murrells, T., Oakley, C., et al. (2009). Patients' supportive care needs beyond the end of cancer treatment: A prospective, longitudinal survey. Journal of Clinical Oncology, 27(36), 6172-6179.

Aubin, M., Vézina, L., Verreault, P., Fillion, L., Hudon, E., Lehman, F., ..., Morin, D. (2011). Patient, primary care physician and specialist expectations of primary care physician involvement in cancer care. Journal of General Internal Medicine, 27(1), 8-15.

Baravelli, C., Krishnasamy, M., Pezaro, C., Schofield, P., Lotfi-Jam, K., Rogers, M., ..., Jefford, M. (2009). The views of bowel cancer survivors and health care professionals regarding survivorship care plans and post treatment follow up. Journal of Cancer Survivorship: Research and Practice, 3(2), 99-108. doi:10.1007/s1176400900861

Beckjord, E.B., Arora, N.K., McLaughlin, W., Oakley-Girvan, I., Hamilton, A.S., \& Hesse, B.W. (2008). Health-related information needs in a large and diverse sample of adult cancer survivors: implications for cancer care. Journal of Cancer Survivorship: Research and Practice, 2(3), 179-189.

Beesley, V., Eakin, E., Steginga, S., Aitken, J., Dunn, J., \& Battistutta, D. (2008). Unmet needs of gynaecological cancer survivors: Implications for developing community support services. Psycho-Oncology, 17(4), 392-400.

Bober, S.L., Recklitis, C.J., Campbell, E.G., Park, E.R., Kutner, J.S., Najita, J.J., \& Diller, L. (2009). Caring for cancer survivors: A survey of primary care physicians. Cancer, 115(Suppl 18), 4409-4418.

Brennan, M.E., Butow, P., Spillane, A.J., \& Boyle, F.M. (2010). Survivorship care after breast cancer: follow-up practices of Australian health professionals and attitudes to a survivorship care plan. Asia-Pacific Journal of Clinical Oncology, 6(2), 116-125.

Brennan, M.E., Gormally, J.F., Butow, P., Boyle, F.M., \& Spillane, A.J. (2014). Survivorship care plans: a systematic review of care plan outcomes. British Journal of Cancer, 111(10), 1899-1908.

Brothers, B.M., Easley, A., Salani, R., \& Andersen, B.L. (2013). Do survivorship care plans impact patients' evaluations of care? A randomized evaluation with gynecologic oncology patients. Gynecologic Oncology, 129(3), 554-558. it provides guidance on how the IFCP could be implemented within the organization. Its exploratory component also details the numerous challenges faced by survivors of endometrial cancers, as they transition to survivorship at the end of treatment. The study also clarifies the need for information on monitoring and managing various long-lasting and late physical symptoms, the need for emotional support and information on the fear of recurrence, and the need for support in adapting to life after cancer. The IFCP seems first and foremost an information tool for the survivor. Its implementation could facilitate the transition by making it easier to respond to various needs, helping to better manage the fear of recurrence, and nurturing empowerment by clarifying desirable behaviours. Currently, few cancer survivors have access to such an IFCP. Phase 2 of our process proposes a study looking into the feasibility and usefulness of making the IFCP available at the end of treatment.

\section{CONFLICTS OF INTEREST}

The authors have no potential conflicts of interest.

Brown, B.B. (1968). Delphi Process: A methodology used for the elicitation of opinions of experts. Santa Monica, California: ASTME Vectors.

Burg, M.A., Lopez, E.D.S., Dailey, A., Keller, M.E., \& Prendergast, B. (2009). The potential of survivorship care plans in primary care follow-up of minority breast cancer patients. Journal of General Internal Medicine, 24(Suppl 2), S467-S471.

Campbell, S.H., Sanson-Fisher, R., Turner, D., Hayward, L., Wang, X.S., \& Taylor-Brown, J. (2011). Psychometric properties of cancer survivors' unmet needs survey. Supportive Care in Cancer, 19(2), 221-230.

Canadian Cancer Society. (2015). Canadian Cancer Statistics. Canadian Cancer Statistics Advisory Committee. Toronto, ON.

Creswell, J.W., \& Plano Clark, V.L. (2011). Designing and conducting mixed methods research. (2nd ed.). Thousand Oaks, CA: SAGE Publications.

Curcio, K.R., Lambe, C., Schneider, S., \& Khan, K. (2012). Evaluation of a cancer survivorship protocol: Transitioning patients to survivors. Clinical Journal of Oncology Nursing 16(4), 400-406.

Dahl, L., Wittrup, I., Vaeggemose, U., Petersen, L.K., \& Blaakaer, J. (2013). Life after gynecologic cancer- A review of patient's quality of life, needs, and preferences in regard to follow-up. International Journal of Gynecological Cancer, 23(2), 227-234.

Dulko, D., Pace, C.M., Dittus, K.L., Sprague, B.L., Pollack, L.A., Hawkins, N.A., \& Geller, B.M. (2013). Barriers and facilitators to implementing cancer survivorship care plans. Oncology Nursing Forum, 40(6), 575-580.

Epstein, R.M., \& Street, R.L. (2007). Patient-centered communication in cancer care: Promoting healing and reducing suffering. National Cancer Institute (NCI). Bethesda, MD: NIH Publication.

Faul, L.A., Rivers, B., Shibata, D., Townsend, I., Cabrera, P., Quinn, G.P., \& Jacobsen, P.B. (2012). Survivorship care planning in colorectal cancer: Feedback from survivors \& providers. Journal of Psychosocial Oncology, 30(2), 198-216.

Fillion, L., Cook, S., Blais, M.C., Veillette, A.M., Aubin, M., de Serres, M., Rainville, F., ..., Fournier, B. (2011). Implementation of screening distress with professional cancer navigators. Oncologie, 13, 277-289.

Fitch, M.I. (1994). Providing supportive care for individuals living with cancer. Toronto. Ontario Cancer Treatment and Research Foundation. 
Fitch, M.I., Porter, H.B., \& Page, B.D. (2008). Supportive care framework: A foundation for person-centred care. Toronto, Ontario: Pappin Communications.

Fitch, M.I., \& Steele, R. (2010). Identifying supportive care needs of women with ovarian cancer. Canadian Oncology Nursing Journal, 20(2), 66-74.

Forsythe, L.P., Parry, C., Alfano, C.M., Kent, E.E., Leach, C.R., Haggstrom, D.A., ..., Rowland, J.H. (2013). Use of survivorship care plans in the United States: associations with survivorship care. Journal of the National Cancer Institute, 105(20), 1579-1587.

Greimel, E., Lahousen, M., Dorfer, M., Lambauer, M., \& Lang, U. (2011). Patients' view of routine follow-up after gynecological cancer treatment. European Journal of Obstetrics \& Gynecology and Reproductive Biology, 159(1), 180-183.

Grover, S., Hill-Kayser, C., Vachani, C., Hampshire, K., DiLullo, G.A., \& Metz, J.M. (2012). Patient reported late effects of gynecological cancer treatment. Gynecologic Oncolog $\gamma$, 124(3), 399-403.

Haq, R., Heus, L., Baker, N.A., Dastur, D., Leung, F-H., Leung, E., Li, B., Vu, K., \& Parsons, J.A. (2013). Designing a multifaceted survivorship care plan to meet the information and communication needs of breast cancer patients and their family physicians: results of a qualitative pilot study. BMC medical informatics and decision making, 13(76). doi: 10.1186/1472-6947-13-76

Harrington, C.B., Hansen, J.A., Moskowitz, M., Todd, B.L., \& Feuerstein, M. (2010). It's not over when it's over: long-term symptoms in cancer survivors-A systematic review. International Journal of Psychiatry in Medicine, 40(2), 163-181.

Hewitt, M., Greenfield, S., \& Stovall, E. (2006). From cancer patient to cancer survivor: Lost in transition. Washington DC: The National Academies Press.

Howell, D., Hack, T.F., Oliver, T.K., Chulak, T., Mayo, S., Aubin, M., ..., Sinclair, S. (2011). Survivorship services for adult cancer population: A Pan-Canadian guideline. Current Oncology, 18(6), e265-e281.

Jefford, M., Lotfi-Jam, K., Baravelli, C., Grogan, S., Rogers, M., Krishnasamy, M., ..., Schofield, P. (2011). Development and pilot testing of a nurse-led posttreatment support package for bowel cancer survivors. Cancer Nursing, 34(3), E1-E10.

Jones, J.M., Ferguson, S., Edwards, E., Walton, T., McCurdy, N., \& Howell, D. (2012). Experiences of care delivery: endometrial cancer survivors at end of treatment. Gynecologic Oncology, 124(3), 458-464.

Jones, J.M., \& Grunfeld, E. (2011). Specific challenges in optimizing health care for cancer survivors. In M. Feuerstein \& P.A. Ganz (Eds.), Health services for cancer survivors: Practice, policy and research. New York: Springer, 3-25.

Landier, W. (2009). Survivorship care: essential components and models of delivery. Oncology (Williston Park), 23(Suppl Nurse Ed), 46-53.

Marbach, T.J., \& Griffie, J. (2011). Patient preferences concerning treatment plans, survivorship care plans, education, and support services. Oncology Nursing Forum, 38(3), 335-342.

Mayer, D.K., Gerstel, A., Leak, A.N., \& Smith, S.K. (2012). Patient provider preferences for survivorship care plan. Journal of Oncology Practice, 8(4), e80-86. doi:10.1200/JOP.2011.000401

McCorkle, R., Ercolano, E., Lazenby, M., Schulman-Green, D., Schilling, L.S., Lorig, K., \& Wagner, E.H. (2011). Self-Management: Enabling and empowering patients living with cancer as a chronic illness. Cancer journal for clinicians, 61(1), 50-62.

Meleis, A.I., Sawyer, L.M., Im, E.O., Hilfinger Messias, D.K. \& Schumacher, K. (2000). Experiencing transitions: An emerging middle-range theory. Advances in Nursing Science, 23(1), 12-28.
Miles, M.B., \& Huberman, A.M. (2003). Analyse des données qualitatives (2nd ed.). Bruxelles: Groupe De Boeck.

Nicolaije, K.A., Husson, O., Ezendam, N.P., Vos, M.C., Kruitwagen, R.F., Lybeert, M.L., \& van de Poll-Franse, L.V. (2012). Endometrial cancer survivors are unsatisfied with receive information about diagnosis, treatment and follow-up: A study from the population-based PROFILES registry. Patient Education and Counseling, 88(3), 427-435.

Osborne, R.H., Elsworth, G.R., \& Whitfield, K. (2007). The health Education Impact Questionnaire (heiQ): An outcomes and evaluation measure for patient education and self-management interventions for people with chronic conditions. Patient Education and Counseling, 66(2), 192-201.

Papadakos, J., Bussière-Côté, S., Abdelmutti, N., Catton, P., Friedman, A.J., Massey, C., Urowitz, S., \& Ferguson, S.E. (2012). Informational needs of gynecologic cancer survivors. Gynecologic Oncology, 124(3), 452-457.

Patton M.Q. (1997). Utilization-focused evaluation: The new century text (3rd ed.). Thousand Oaks, CA: Sage Publications.

Sabatino, S.A., Thompson, T.D., Smith, J.L., Rowland, J.H., Forsythe, L.P., Pollack, L., \& Hawkins, N.A. (2013). Receipt of cancer treatment summaries and follow-up instructions among adult cancer survivors: results from a national survey. Journal of Cancer Survivorship, 7, 32-43.

Salani, R. (2013). Survivorship planning in gynecologic cancer patients. Gynecologic Oncology, 130(2), 389-397.

Simard, S., \& Savard, J. (2015). Screening and comorbidity of clinical levels of fear of cancer recurrence. Journal of Cancer Survivorship: Research and Practice, 9(3), 481-491. doi:10.1007/s1176401504244

Simard, S., Thewes, B., Humphris, G., Dixon, M., Hayden, C., Mireskandari, S., \& Ozakinci, G. (2013). Fear of cancer recurrence in adult cancer survivors: a systematic review of quantitative studies. Journal of Cancer Survivorship: Research and Practice, 7(3), 300-322.

Smith, S.L., Singh-Carlson, S., Downie, L., Payeur, N., \& Wai, E.S. (2011). Survivors of breast cancer: patient perspectives on survivorship care planning. Journal of Cancer Survivorship: Research and Practice, 5(4), 337-344.

Sprague, B.L., Dittus, K.L., Pace, C.M., Dulko, D., Pollack, L.A., Hawkins, N.A., \& Geller, B.M. (2013). Patient satisfaction with breast and colorectal cancer survivorship care plans. Clinical Journal of Oncology Nursing, 17(3), 266-272.

Steele, R., \& Fitch, M.I. (2008). Supportive care needs of women with gynecologic cancer. Cancer Nursing, 31(4), 284-291.

Stricker, C.T., Jacobs, L.A., Risendal, B., Jones, A., Panzer, S., Ganz, P.A., ..., Palmer, S.C. (2011). Survivorship care planning after the Institute of Medicine recommendations: How are we faring? Journal of Cancer Survivorship: Research and Practice, 5(4), 358-370. doi:10.1007/s1176401110964

Thorne, S.E., \& Stajduhar, K.I. (2012). Patient perceptions of communications on the threshold of cancer survivorship: Implications for provider responses. Journal of Cancer Survivorship: Research and Practice, 6(2), 229-237.

Vaz, A.F., Conde, D.M., Costa-Paiva, L., Morais, S.S., Esteves, S.B. \& Pinto-Neto, A.M. (2011). Quality of life and adverse events after radiotherapy in gynecologic cancer survivors: A cohort study. Archives of Gynecology and Obstetrics, 284(6), 1523-1531.

Vollrath, M., Zenger, M., Singer, S., Einenkel, J., \& Hinz, A. (2013). The course of fatigue in patients with gynecologic and breast cancer. Journal of Gynecologic Oncology, 24(3), 280-286.

Wu, H.S., \& Harden, J.K. (2015). Symptom burden and quality of life in survivorship: A review of literature. Cancer Nursing, 38(1), E29-E54. 